Advance Journal of Food Science and Technology 14(6): 166-180, 2018

DOI:10.19026/ajfst.14.5978

ISSN: 2042-4868; e-ISSN: 2042-4876

(C) 2018 Maxwell Scientific Publication Corp.

Submitted: April 23, 2018

Accepted: June 27, 2018

Published: October 25, 2018

\title{
Research Article \\ Technologies for Extracting Anthocyanins from the Red Raspberry and their Free Radical Scavenging Ability
}

\author{
${ }^{1}$ Ying Liu, ${ }^{2}$ Xuemei Zhang, ${ }^{2} \mathrm{Han} \mathrm{Li},{ }^{1}$ Shuang Gao, ${ }^{1}$ Lixia Wang and ${ }^{1}$ Yiling Tian \\ ${ }^{1}$ College of Food Science and Technology, \\ ${ }^{2}$ College of Forestry, Agricultural University of Hebei, Baoding 071000, China
}

\begin{abstract}
The aims of study was to find the best technology for extracting anthocyanins from the red respberry. Different technologies for the preliminary extraction of anthocyanins from red raspberry fruit as the raw material, including Ultrasound-Assisted Extraction (UAE) and Microwave-Assisted Extraction (MAE), were studied. The effects of extraction time, extraction temperature, solvent-material ratio and other factors on the anthocyanin yield were investigated. The center point combination experiment design was used to analyze the various extraction conditions, determine significance and interactions between various factors and optimize the extraction parameters. The final extraction rate obtained using MAE $(0.0598 \mathrm{mg} / \mathrm{g})$ was about 1.5 -fold higher than that using UAE $(0.0412$ $\mathrm{mg} / \mathrm{g}$ ). The free radical scavenging activity of the extracts was examined in different in-vitro antioxidant experiments in comparison with ascorbic acid $(\mathrm{Vc})$ as the control. In these DPPH (2,2-diphenyl-1-picrylhydrazyl), hydroxyl and ABTS (2,2'-azino-bis (3-ethylbenzothiazoline-6-sulfonic acid)) free radical scavenging experiments, MAE and UAE extracts showed free radical scavenging activities 2.8 and 1.5-fold, 4.7 and 3-fold and 1.2 and 1-fold higher, respectively, than those of the Vc control. Furthermore, the scavenging activities of red raspberry anthocyanin extracts against the different free radicals increased in the order hydroxyl $>$ ABTS $>$ DPPH, while the antioxidant capacity of the MAE extract was higher than that of the UAE extract.
\end{abstract}

Keywords: Antioxidant experiments, anthocyanin, red raspberry, response surface methodology, ultrasoundassisted extraction

\section{INTRODUCTION}

In recent decades, color has been used as a significant index for evaluating food. Although synthetic pigments have been widely used as colorbrightening food additives, some are poisonous. Anthocyanins, a class of natural pigments widely found in many fruits, vegetables and plants, are favored by consumers because they are safe, nontoxic. Anthocyanins are water-soluble and have beneficial properties, including improving blood circulation, antioxidant activity, preventing ulcers and antiinflammatory effects. Therefore, the use of anthocyanins as natural pigments should be the subject of further research (Mazur et al., 2014; Jean-Gilles et al., 2012; Sun, 2006).

Red raspberry (Rubus idaeus L.) is cultivated and used in food production worldwide owing to its good flavor, bright color and unique value (De Souza et al., 2014a; Shi et al., 2009). Tosun et al. (2009) have shown that red raspberries are rich in various nutrients. They also contain various active ingredients, including flavonoids, anthocyanins and ellagic acid, that have free radical inhibition and scavenging properties, improve immunity, have antitumor and anticancer effects and protect liver function (Wang et al., 2015; Figueira et al., 2014; Jakobek and Seruga, 2012; Xiao-Ping et al., 2010; Hernández-Herrero and Frutos, 2011; Seeram et al., 2006). Ozarda et al. (2015) found that red raspberry extract had a very high antioxidant capacity and can be used as an antioxidant in fruit drinks. Furthermore, De Souza et al. (2014b) found that red raspberry and other berries had very high antioxidant and biological activities. The above studies demonstrate that the properties and activities of red raspberry are interesting topics for further research.

Anthocyanin extraction from fruits or plants is commonly achieved using organic solvent extraction or thermal extraction methods. Organic solvent extraction requires a long extraction time and has low efficiency, while thermal extraction involves a long heating period that decreases the stability and degrades the biological activity of anthocyanins. Recently, many new extraction methods have been developed, including

Corresponding Author: Yiling Tian, College of Food Science and Technology, Agricultural University of Hebei, Baoding 071000, China

This work is licensed under a Creative Commons Attribution 4.0 International License (URL: http://creativecommons.org/licenses/by/4.0/). 
Microwave-Assisted Extraction (MAE) and Ultrasound-Assisted Extraction (UAE). Using MAE with red raspberry as the raw material, Yuan et al. (2011) reported a pigment extraction rate of $95.31 \%$ and showed that this method had high feasibility, while Dong et al. (2014), using UAE combined with ethanol extraction, confirmed the content and purity of anthocyanins. Several authors have reported the advantages of MAE and UAE compared with conventional extraction, such as reduced extraction time, lower organic solvent and energy demand and higher yield. However, during microwave or ultrasound treatment, the temperature and pressure in the cell can increase to levels that result in cell wall rupture. Owing to the many uncertain factors remaining, these methods require optimization.

Response Surface Methodology (RSM) is widely used to analyze the impact of and relationship between, factors (Chen et al., 2014), with many studies reporting that RSM is useful for analyzing, improving and optimizing processes. In this study, the effects of MAE parameters, including microwave power, microwave time and solvent-material ratio and UAE parameters, including ultrasound time, ultrasound temperature and solvent-material ratio, are assessed. Wang et al. (2015) previously authenticated that the method was reliable using a single-factor experiment combined with RSM experiments. Therefore, the aim of this study was to compare MAE and UAE processes using response surface methodology.

\section{MATERIALS AND METHODS}

Raw materials: Red raspberry (Rubus idaeus L.) was purchased in Xingtai (Hebei, China). The fruit was stored in a freezer at $-20^{\circ} \mathrm{C}$ until extraction. The moisture content of fresh red raspberry was $82.12 \%$.

Chemicals: Analytical-grade ethanol, hydrochloric acid, potassium chloride, sodium acetate were purchased from Tianli Chemical Co., Ltd. (Tianjin, China).

Extraction procedures: Frozen red raspberry sample $(1 \mathrm{~g})$ was ground and placed into a flask and $1.5 \mathrm{M}$ HCl-95\% ethanol $(15: 85, \mathrm{v} / \mathrm{v} ; 40 \mathrm{~mL})$ was added. Extraction was then performed using different UAE and MAE parameters (see below), followed by centrifugation and filtration to obtain the preliminary raspberry extract of anthocyanins.

MAE of anthocyanins: The following parameters were used in the MAE procedure: Microwave time: 20, 40, 60 and $80 \mathrm{sec}$; microwave power: 200, 400, 600 and $800 \mathrm{~W}$; solvent-material ratio: 20:1, 30:1, 40:1 and 50:1 (v/w), respectively.

UAE of anthocyanins: The following parameters were used in the UAE experiments: Ultrasonication time: 10,
15, 20 and $25 \mathrm{~min}$; ultrasonication temperature: 20, 30, 40 and $50^{\circ} \mathrm{C}$; solvent-material ratio: $20: 1,30: 1,40: 1$ and 50:1, respectively.

Determination of anthocyanin content: Anthocyanin contents obtained from MAE and UAE were determined using a $\mathrm{pH}$ differential method (Chen et al., 2011) and calculated using Eq. (1):

$$
\mathrm{C}(\mathrm{mg} / \mathrm{g})=\left(\mathrm{A}_{0}-\mathrm{A}_{1}\right) \times \mathrm{V} \times n \times \mathrm{M} /(\varepsilon \times \mathrm{m})
$$

where,

C : The anthocyanin content $(\mathrm{mg} / \mathrm{g})$

$\mathrm{A}_{0}$ and $\mathrm{A}_{1}$ : The absorbances at $530 \mathrm{~nm}$ measured at $\mathrm{pH} 1.0$ and 4.5 , respectively

M : The molecular weight of cyanidin-3glucoside $(M=449.2)$

$\varepsilon \quad:$ The extinction coefficient of cyanidin-3glucoside $(26,900)$

$\mathrm{m} \quad$ : The weight of the dry anthocyanin sample (g)

$\mathrm{V} \quad$ : The volume of the anthocyanin solution $(\mathrm{mL})$

Experimental design and optimization: RSM was used to determine the optimum conditions for anthocyanin extraction from red raspberry. The experimental parameters studied for MAE were microwave power $\left(\mathrm{X}_{1}, \mathrm{~W}\right)$, microwave time $\left(\mathrm{X}_{2}, \mathrm{~S}\right)$ and solvent-material ratio $\left(X_{3}, g / m L\right)$. For UAE, the experimental factors studied were ultrasound time $\left(\mathrm{X}_{4}\right.$, $\mathrm{min})$, ultrasound temperature $\left(\mathrm{X}_{5},{ }^{\circ} \mathrm{C}\right)$ and the solventmaterial ratio $\left(\mathrm{X}_{6}, \mathrm{~g} / \mathrm{mL}\right)$. The results of all experiments focused on the extracted anthocyanin content, $\mathrm{R}(\mathrm{mg} / \mathrm{g})$. All data was analyzed using RSM 8.0.6.0 experimental design software.

Each experiment consisted of 17 runs (Table 1), comprising twelve runs to analyze the influence of each factor and five replicates at the center points to evaluate the model validity. To avoid system errors influencing the experiments, the experiments were performed in a random order, as shown in Table 1.

In the central composite experiment, the combination of multiple linear regression equations and polynomial equations was used to obtain more convincing test results. The multiple linear regression model is described in Eq. (2):

$$
\begin{aligned}
& \mathrm{R}=\beta 0+\beta 1 \mathrm{~A}+\beta 2 \mathrm{~B}+\beta 3 \mathrm{C}+\beta 4 \mathrm{AB}+\beta 5 \mathrm{AC}+ \\
& \beta 6 \mathrm{BC}+\beta 7 \mathrm{~A}^{2}+\beta 8 \mathrm{~B}^{2}+\beta 9 \mathrm{C}^{2}
\end{aligned}
$$

where,

$\mathrm{R} \quad$ : The anthocyanin content (dependent variable)

$\beta_{\mathrm{i}}$ : The named regression coefficients of the equation

Optimization of the experimental conditions combined all of the above parameters and the effect of the various factors. 
Adv. J. Food Sci. Technol., 14(6): 166-180, 2018

Table 1: Design and results of response surface analysis of MAE and UAE

\begin{tabular}{|c|c|c|c|c|c|c|c|c|}
\hline \multirow[b]{2}{*}{ Num. } & \multicolumn{4}{|c|}{ Factors of MAE } & \multicolumn{4}{|c|}{ Factors of UAE } \\
\hline & $\mathrm{X}_{1}(\mathrm{~W})$ & $\mathrm{X}_{2}(\mathrm{~S})$ & $\mathrm{X}_{3}(\mathrm{~g} / \mathrm{mL})$ & $\mathrm{R}(\mathrm{mg} / \mathrm{g})$ & $X_{1}(\min )$ & $\mathrm{X}_{2}\left({ }^{\circ} \mathrm{C}\right)$ & $\mathrm{X}_{3}(\mathrm{~g} / \mathrm{mL})$ & $\mathrm{R}(\mathrm{mg} / \mathrm{g})$ \\
\hline 1 & 400 & 40 & $1: 40$ & 0.0542 & 20 & 50 & 30 & 0.0134 \\
\hline 2 & 400 & 60 & $1: 30$ & 0.0632 & 10 & 30 & 30 & 0.0205 \\
\hline 3 & 200 & 60 & $1: 20$ & 0.0392 & 20 & 40 & 40 & 0.0226 \\
\hline 4 & 400 & 60 & $1: 30$ & 0.0529 & 20 & 40 & 20 & 0.0273 \\
\hline 5 & 400 & 60 & $1: 30$ & 0.0498 & 15 & 40 & 30 & 0.0358 \\
\hline 6 & 400 & 60 & $1: 30$ & 0.0512 & 15 & 40 & 30 & 0.0379 \\
\hline 7 & 400 & 60 & $1: 30$ & 0.0604 & 15 & 50 & 40 & 0.0191 \\
\hline 8 & 600 & 60 & $1: 40$ & 0.0502 & 15 & 30 & 20 & 0.0231 \\
\hline 9 & 400 & 80 & $1: 20$ & 0.0378 & 10 & 40 & 40 & 0.0428 \\
\hline 10 & 400 & 40 & $1: 20$ & 0.0296 & 15 & 40 & 30 & 0.0339 \\
\hline 11 & 200 & 60 & $1: 40$ & 0.0419 & 10 & 50 & 30 & 0.0237 \\
\hline 12 & 600 & 60 & $1: 20$ & 0.0398 & 10 & 40 & 20 & 0.0340 \\
\hline 13 & 600 & 80 & $1: 30$ & 0.0432 & 20 & 30 & 30 & 0.0431 \\
\hline 14 & 400 & 80 & $1: 40$ & 0.0362 & 15 & 40 & 30 & 0.0366 \\
\hline 15 & 600 & 40 & $1: 30$ & 0.0496 & 15 & 40 & 30 & 0.0433 \\
\hline 16 & 200 & 40 & $1: 30$ & 0.0373 & 15 & 50 & 20 & 0.0193 \\
\hline 17 & 200 & 80 & $1: 30$ & 0.0443 & 15 & 30 & 40 & 0.0397 \\
\hline
\end{tabular}

Verification of experiment and model: The MAE and UAE conditions were optimized using RSM. The best extraction conditions and predictive value were used to validate the experiments. The practicability of the test model and the regression equation were judged using the test results.

Antioxidant activity: The antioxidant activity of the extracts was determined using ABTS, DPPH and hydroxyl $(\cdot \mathrm{OH})$ radicals. The scavenging mechanism of antioxidants reacting with free radicals was found to be complex, with the sample concentration and clearance rate not showing a simple linear relationship and the complete free radical scavenging rate curve showing ' $S$ '-type characteristics. The half-clearance (inhibition) concentration (EC50) is the sample concentration at which the clearance rate is $50 \%$ and is a scientific index that evaluates the ability of antioxidants to clear free radicals. From the EC50, the free radical scavenging activity (AE) can be calculated using $\mathrm{AE}=1 / \mathrm{EC} 50 . \mathrm{AE}$ can be used to analyze the antioxidant ability of free radical scavengers, with a larger $\mathrm{AE}$ value representing a stronger ability to remove free radicals. These $\mathrm{AE}$ values were used to evaluate the antioxidant ability of each sample in vitro (Xiao et al., 2011).

DPPH: DPPH in alcohol solution has a deep purple color, with a strong absorption peak at $517 \mathrm{~nm}$. When a free radical scavenger is added to the DPPH solution, the solution color changes owing to the pairing effect of a single electron. Therefore, the absorbance value at the maximum absorption wavelength also changes, which allows the ability to clear the DPPH radical to be evaluated. In a pre-experiment, the suitable concentration range for the DPPH solution and the sample to be tested was explored, with the final tests conducted in this concentration range. For MAE of raspberry anthocyanins, concentrations of $12.5,15$, $17.5,20$ and $25 \mu \mathrm{g} / \mathrm{mL}$, respectively were selected for further experiments, while for UAE of raspberry anthocyanins, concentrations of 7.5, 10, 12.5, 15 and $17.5 \mu \mathrm{g} / \mathrm{mL}$, respectively were selected for further experiments. Samples at each concentration were prepared for testing by adding the sample solution (1 $\mathrm{mL}$ ) and DPPH solution ( $3 \mathrm{~mL}, 50 \mathrm{ppm})$ to a test tube and shaken in the dark at room temperature (light reaction time, $30 \mathrm{~min}$ ). The solution was transferred to a cuvette, zeroing with distilled water and the absorbance at $517 \mathrm{~nm}$ was measured using UV spectrophotometry. Sample solution $(1 \mathrm{~mL})$ in anhydrous ethanol $(3 \mathrm{~mL})$ in another tube was used as the control. In a third test tube, ethanol $(1 \mathrm{~mL})$ and DPPH solution ( $3 \mathrm{~mL}$ ) were combined for use as a blank control. Each test was repeated three times, with the average value taken as the final result. The fitting equation of EC50, according to the conversion $\mathrm{AE}=$ 1/EC50, was used to calculate the clearance rate (Eq. 3):

$$
\text { Clearance rate }(\%)=\left(1-\frac{A \mathrm{c}-A d}{\mathrm{Ak}}\right) \times 100 \%
$$

where,

Ac : The absorbance of the sample-DPPH mixture

Ad : The absorbance of the sample-absolute ethanol mixture

Ak : The absorbance of the absolute ethanol-DPPH mixture

-OH: In the in-vitro determination of antioxidant activity, hydroxyl free radical scavenging is commonly used as a test index to accurately evaluate antioxidant ability. The purpose of this study is to explore and compare the inhibition of and changes in hydroxyl radicals caused by extracted samples to reasonably evaluate their antioxidant activities. To ensure the test results were more accurate and reliable, the tests were performed using a kit method, with each reagent 
preparation method and addition amount, operation steps and other matters requiring close attention determined by the kit, which ensured the purity of each reagent. This approach also avoided some unnecessary operation errors and obtained test results that were more credible. First, a suitable concentration ranges for the samples to be tested was determined and the sample concentration was then adjusted using this range.

For the MAE of raspberry anthocyanins, concentrations of $325,350,375,400$ and $425 \mu \mathrm{g} / \mathrm{mL}$, respectively were selected, while for UAE of raspberry anthocyanins, concentrations of 180,200, 220, 240 and $260 \mu \mathrm{g} / \mathrm{mL}$, respectively were selected for further experiments. By following the kit, each reagent addition order and sample volume was consistent with the instructions, which were strictly followed to ensure correct operation and avoid test errors caused by human error. In this experiment, the scavenging ability of free radicals was analyzed and compared with the half clearance concentration (EC50). It is necessary to know the clearance rate of hydroxyl radicals in each sample, so the operation steps of the kit are only required for the tube, the measurement tube and the control group with Vc. Each test was repeated three times and the average value was taken as the final result. The fitting equation of EC50, according to the conversion $\mathrm{AE}=1 / \mathrm{EC} 50$, was used to calculate the clearance rate (Eq. 4):

$$
\text { Clearance rate }(\%)=\frac{A \mathrm{~d}-(A c-A b)}{\mathrm{Ad}} \times 100 \%
$$

where,

Ac : The absorbance of the sample-DPPH mixture

Ad : The absorbance of the sample-absolute ethanol mixture

$\mathrm{Ab}:$ The absorbance of the blank solution

ABTS $^{+}$: Principle of the ABTS method for the determination of total antioxidant capacity, ABTS under the appropriate oxidant oxidation into green ABTS+, in the presence of antioxidants ABTS+ suppressed, at 414 or $734 \mathrm{~nm}$ determine the wavelength of determination of ABTS+ absorbance can be determination of total antioxidant capacity and calculate the sample.

Chose after microwave-assisted extraction of raspberry anthocyanins extract from concentration: 10, $15,20,25$ and $30 \mathrm{ug} / \mathrm{mL}$, respectively, besides selection of ultrasound-assisted extraction raspberry anthocyanins extract concentrations 5, 8, 11, 14 and 17 $\mathrm{ug} / \mathrm{mL}$, respectively for further experiment. $7 \mathrm{mmol} / \mathrm{L}$ ABTS and $2.45 \mathrm{mmol} / \mathrm{L}$ potassium sulfate by volume 1:1 mixture. Shake, room temperature placing for $24 \mathrm{~h}$ with anhydrous ethanol dilution to in wavelength determine the wavelength of absorption for $0.7+0.02$, as ABTS solution was determined. Were precisely taken with volume fraction of $95 \%$ ethanol diluted to certain concentration of raspberry extract of $400 \mathrm{~m} \mathrm{l}$, adding ABTS assay solution $3.6 \mathrm{~mL}$, standing for 5 min, to determine the wavelength of the wavelength absorbance was measured. Each test was repeated three times and the average value was taken as the final result. The fitting equation of EC50, according to the $\mathrm{AE}=1 / \mathrm{EC} 50$ conversion value of $\mathrm{AE}$. According to the following formula to calculate the clearance rate:

$$
\text { Clearance rate }(\%)=\left(1-\frac{A i-A j}{\mathrm{Ac}}\right) \times 100 \%
$$

where,

Ai : The absorbance of a mixture of sample solution and $\mathrm{ABTS}^{+}$solution

Ac : The absorbance of the control group

$\mathrm{Aj}$ : The absorbance of the sample added

\section{RESULTS AND DISCUSSION}

MAE results: Figure 1 shows the effect of different MAE conditions on the anthocyanin yield. As shown in Fig. 1a, because of microwave itself with the molecular dipole generated in the electromagnetic field in resonant frequency and high-speed rotating heat effect. This enabled the extraction liquid temperature to rise rapidly and increased the solubility of raspberry anthocyanins. However, when the microwave intensity was too high, the solution temperature became too high, which caused the anthocyanins to undergo thermal oxidation and decomposition, resulting in a gradual decrease in anthocyanin yield.

As shown in Fig. 1b, after the extraction of anthocyanins had plateaued, extending the extraction time led to hydrolysis of the anthocyanins, which reduced their yield. Furthermore, a long extraction time would make the extraction liquid temperature too high, resulting in structural modification of anthocyanins, decomposition and excess impurities becoming dissolved, thereby reducing the anthocyanin yield.

As shown in Fig. 1c, as the solvent-material ratio increased, a gradual decrease in the anthocyanin yield was observed. This phenomenon might be due to ethanol affecting microwave extraction in two ways. Firstly, the concentration of ethanol can increase the absorption of microwaves, which is beneficial for pigment extraction. The solvent volume and mass transfer force also increased, which increased the contact area of the materials and solvents, which favored pigment dissolution. Secondly, ethanol concentration over the general assembly caused the extraction temperature to be reduced, which decreases the capacity for pigment extraction. When the solventmaterial ratio is too low, the anthocyanins concentration will be relatively high, resulting in a high residue amounts in the system. Therefore, the material liquid ratio should not be too small. 
Adv. J. Food Sci. Technol., 14(6): 166-180, 2018

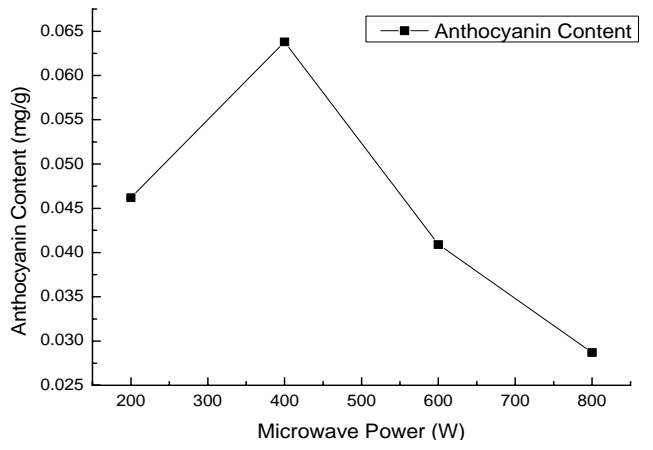

(a)

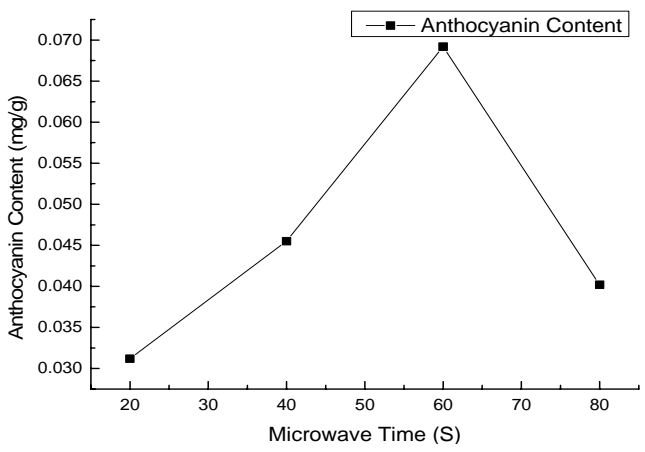

(b)

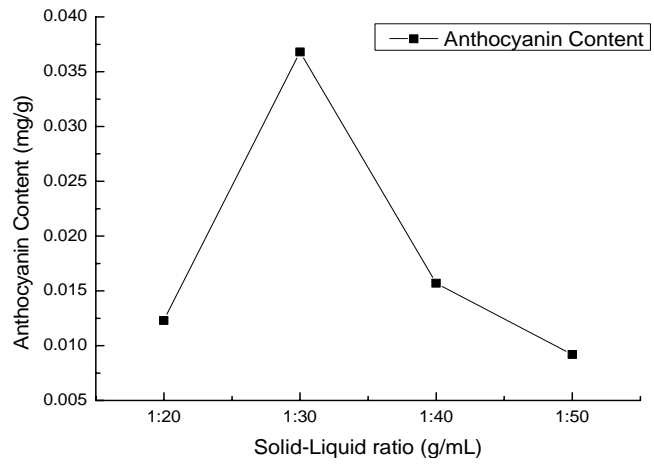

(c)

Fig. 1: Effect of; (a): microwave power; (b): microwave time and; (c): solvent-material ratio on extraction

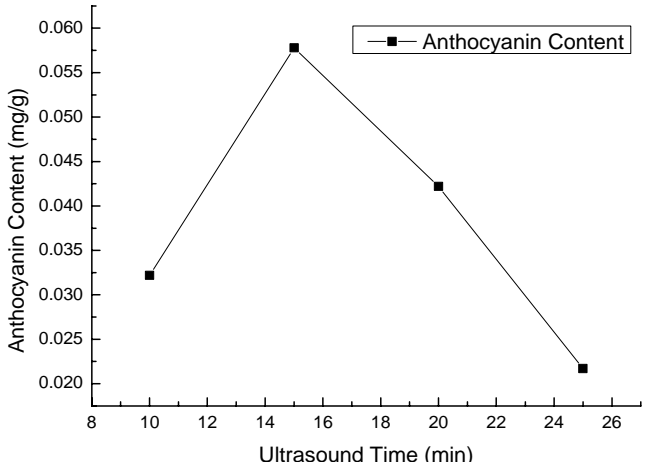

(a)

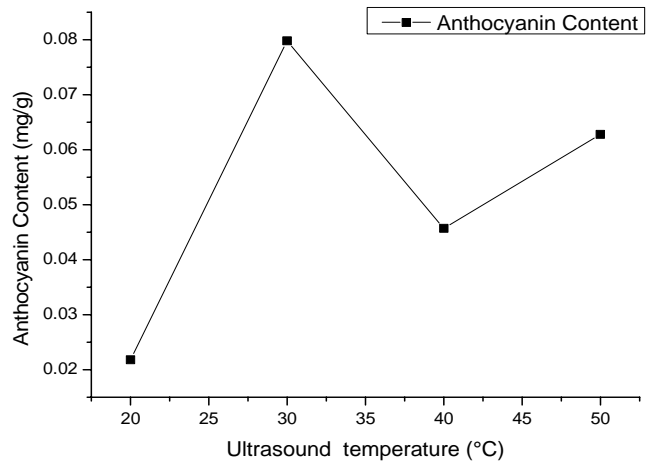

(b)

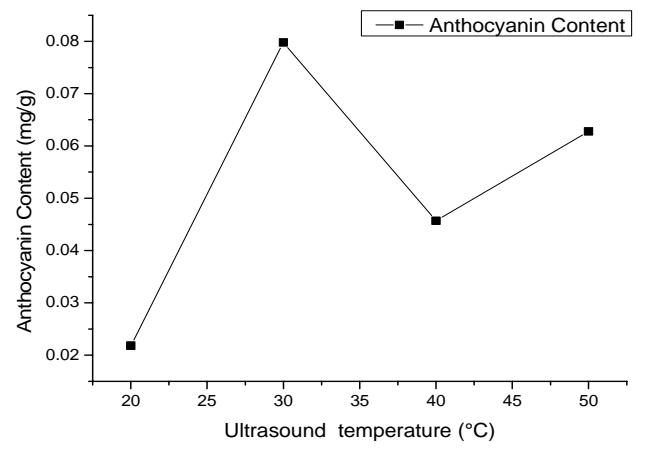

(c)

Fig. 2: Effect of; (a): ultrasound time; (b): ultrasound temperature and; (c): solid-liquid ratio on extraction 
UAE results: The effect of UAE on the anthocyanin yield is shown in Fig. 2. As shown in Fig. 2a, when reaching the saturation point of anthocyanin extraction, essentially all anthocyanins were dissolved. Extending the extraction time would subject the anthocyanin structure to damage, thereby decreasing the extraction rate.

As shown in Fig. 2b, the cavitation effect of ultrasonic waves was combined with the thermal effect during extraction. By increasing the temperature, the cavitation effect of the ultrasound wave decreased and the thermal effect increased. These two effects can produce an optimal combining point at a certain temperature, at which the extraction rate will reach the maximum.

As shown in Fig. 2c, the anthocyanin extraction rate was small before reaching the saturation point. The was mainly due to the amount of solvent being too small to allow complete dissolution. When the amount of extraction solvent was increased, the effect of ultrasonic energy on the cavitation effect of the raw material was reduced, which increased the anthocyanin yield. However, the anthocyanin yield decreased with increasing solvent.

Experimental design and optimization: Optimization of red raspberry MAE conditions using RSM: Using the response surface design software, the quadratic sum, degree of freedom, mean square, F-value, p-value and regression equation analysis of variance were obtained for the MAE of anthocyanins from red raspberry (Table 2).

The regression equation was as follows (Eq. 6):

$$
\begin{aligned}
& \mathrm{R}_{1}=0.055+2.513 \times 10^{-3} \mathrm{X}_{1}-\left(1.037 \times 10^{-3}\right) \mathrm{X}_{2}+ \\
& \left(4.400 \times 10^{-3}\right) \mathrm{X}_{3}-\left(3.350 \times 10^{-3}\right) \mathrm{X}_{1} \mathrm{X}_{2}+\left(1.925 \times 10^{-3}\right) \\
& \mathrm{X}_{1} \mathrm{X}_{3}-\left(6.775 \times 10^{-3}\right) \mathrm{X}_{2} \mathrm{X}_{3}-\left(4.4400 \times 10^{-3}\right) \mathrm{X}_{1}^{2}- \\
& \left(7.500 \times 10^{-3}\right) \mathrm{X}_{2}^{2}-\left(8.325 \times 10^{-3}\right) \mathrm{X}_{3}^{2}
\end{aligned}
$$

According to the data shown in Table 2, the microwave power, microwave time and solventmaterial ratio of the extract had a significant effect on the anthocyanin contents in the red raspberry extracts. The model significance test p-value was significant, while the lack of fit p-value was not significant, demonstrating that the model and the test fitted well and that the model better described the factors and the real relationship between the response values. The degree of influence of each variable on the experiment decreased in the following order: microwave power with microwave time $\left(\mathrm{X}_{1} \times \mathrm{X}_{2}\right)>$ microwave power $\left(\mathrm{X}_{1}\right)$ $>$ microwave power with solvent-material ratio $\left(\mathrm{X}_{1} \times \mathrm{X}_{3}\right)$

\begin{tabular}{|c|c|c|c|c|c|}
\hline Treatments & Quadratic sum & Degree of freedom & M.S. & F-value & p-value \\
\hline Model & $1.133 \mathrm{E}-003$ & 9 & $1.259 \mathrm{E}-004$ & 5.40 & 0.0184 \\
\hline $\mathrm{A}-\mathrm{X}_{1}$ & $5.050 \mathrm{E}-005$ & 1 & $5.050 \mathrm{E}-005$ & 2.17 & 0.1844 \\
\hline $\mathrm{B}-\mathrm{X}_{2}$ & $8.611 \mathrm{E}-006$ & 1 & 8.611E-006 & 0.37 & 0.8784 \\
\hline $\mathrm{C}-\mathrm{X}_{3}$ & $1.549 \mathrm{E}-004$ & 1 & $1.549 \mathrm{E}-004$ & 6.65 & 0.5624 \\
\hline $\mathrm{AB}-\mathrm{X}_{1} \mathrm{X}_{2}$ & 4.489E-005 & 1 & 4.489E-005 & 1.93 & 0.0366 \\
\hline $\mathrm{AC}-\mathrm{X}_{1} \mathrm{X}_{3}$ & $1.482 \mathrm{E}-005$ & 1 & $1.482 \mathrm{E}-005$ & 0.64 & 0.2077 \\
\hline $\mathrm{BC}-\mathrm{X}_{2} \mathrm{X}_{3}$ & $1.836 \mathrm{E}-004$ & 1 & $1.836 \mathrm{E}-004$ & 7.88 & 0.4513 \\
\hline $\mathrm{A}^{2}-\mathrm{X}_{1}^{2}$ & $8.152 \mathrm{E}-005$ & 1 & $8.152 \mathrm{E}-005$ & 3.50 & 0.0263 \\
\hline $\mathrm{B}^{2}-\mathrm{X}_{2}^{2}$ & $2.368 \mathrm{E}-004$ & 1 & $2.368 \mathrm{E}-004$ & 10.16 & 0.0153 \\
\hline $\mathrm{C}^{2}-\mathrm{X}_{3}^{2}$ & $2.918 \mathrm{E}-004$ & 1 & $2.918 \mathrm{E}-004$ & 12.52 & 0.0095 \\
\hline Residual & $1.631 \mathrm{E}-004$ & 7 & $2.330 \mathrm{E}-005$ & & \\
\hline Lack of fit & $2.207 \mathrm{E}-005$ & 3 & $7.356 \mathrm{E}-006$ & 0.21 & 0.8857 \\
\hline Pure error & $1.410 \mathrm{E}-004$ & 4 & $3.526 \mathrm{E}-005$ & & \\
\hline Cor total & $1.296 \mathrm{E}-003$ & 16 & & & \\
\hline
\end{tabular}
$>$ microwave time with solvent-material ratio $\left(\mathrm{X}_{2} \times \mathrm{X}_{3}\right)$ $>$ solvent-material ratio $\left(\mathrm{X}_{3}\right)>$ microwave

Table 2: Variance analysis of regression equation by RSM in the MAE of anthocyanins from red raspberry

M.S.: Mean square

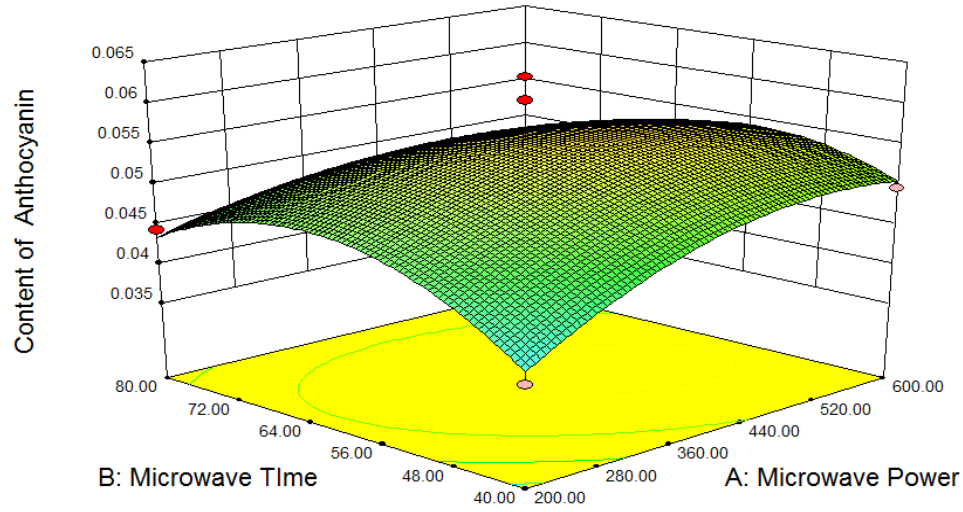

(a) 
Adv. J. Food Sci. Technol., 14(6): 166-180, 2018

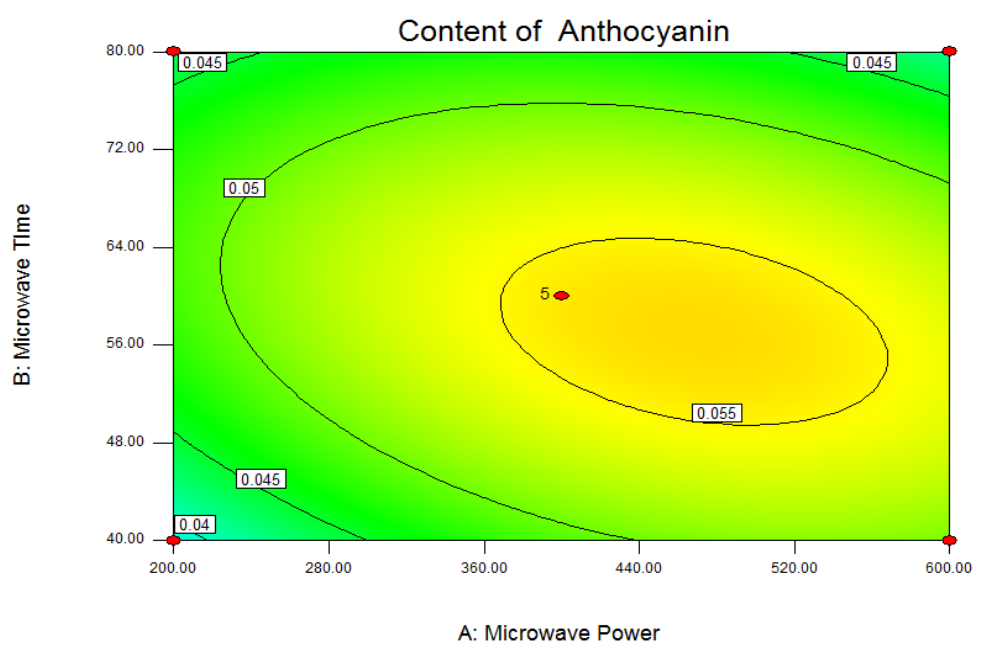

(b)

Fig. 3: 3D surface figure and contour map of the effect of microwave power and time

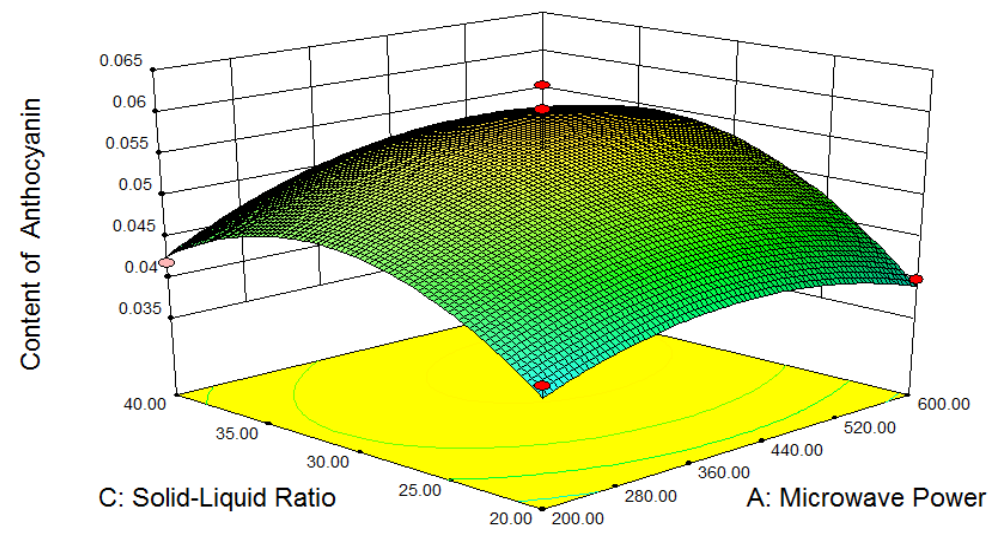

(a)

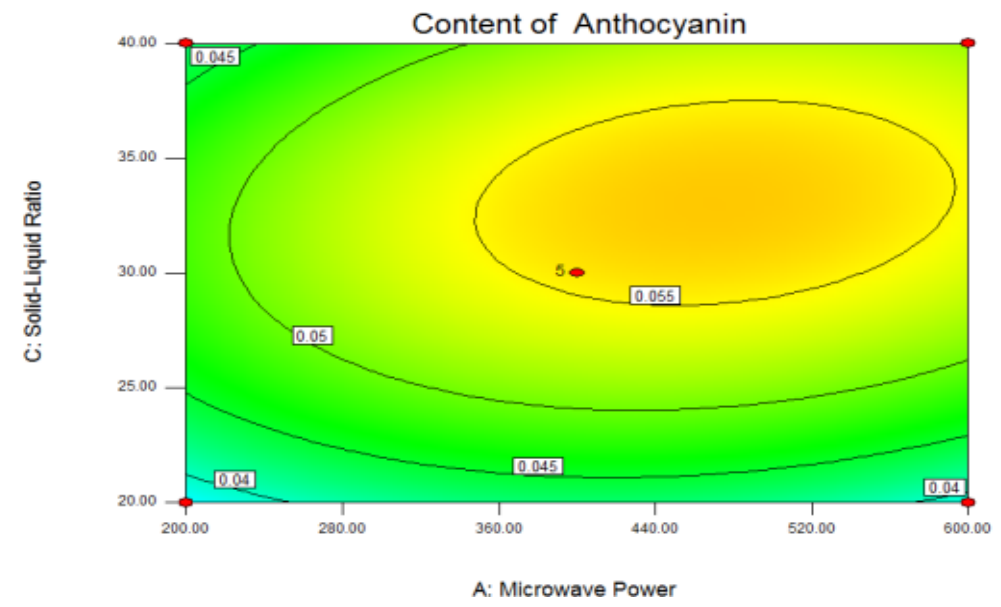

(b)

Fig. 4: 3D surface figure and contour map of the effect of microwave power and solvent-material ratio interaction

time $\left(\mathrm{X}_{2}\right)$. Therefore, microwave power was the variable with the strongest effect on the MAE process, while the microwave time had a weaker effect than microwave power on the MAE process. The 3D surface figures and contour maps of each variable are shown in Fig. 3 to 5 . 


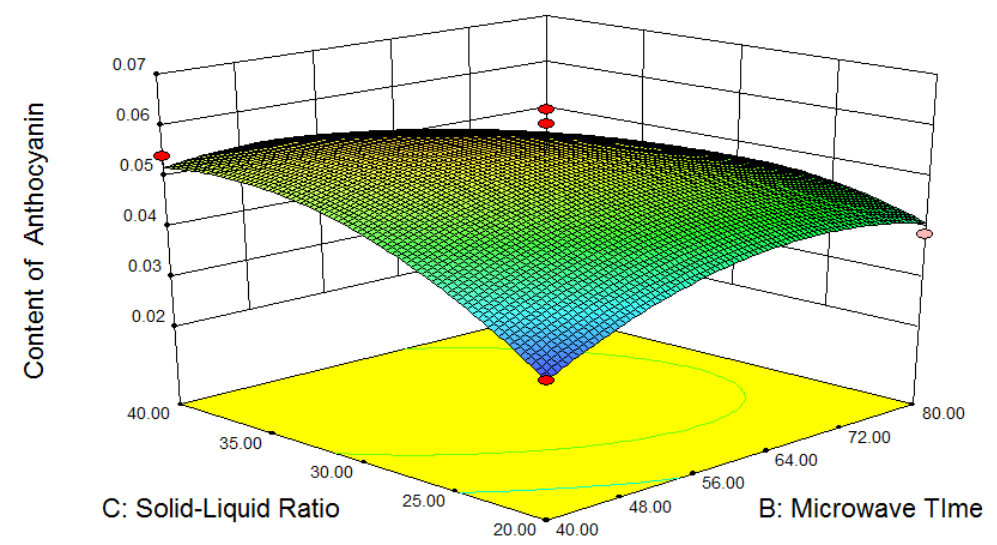

(a)

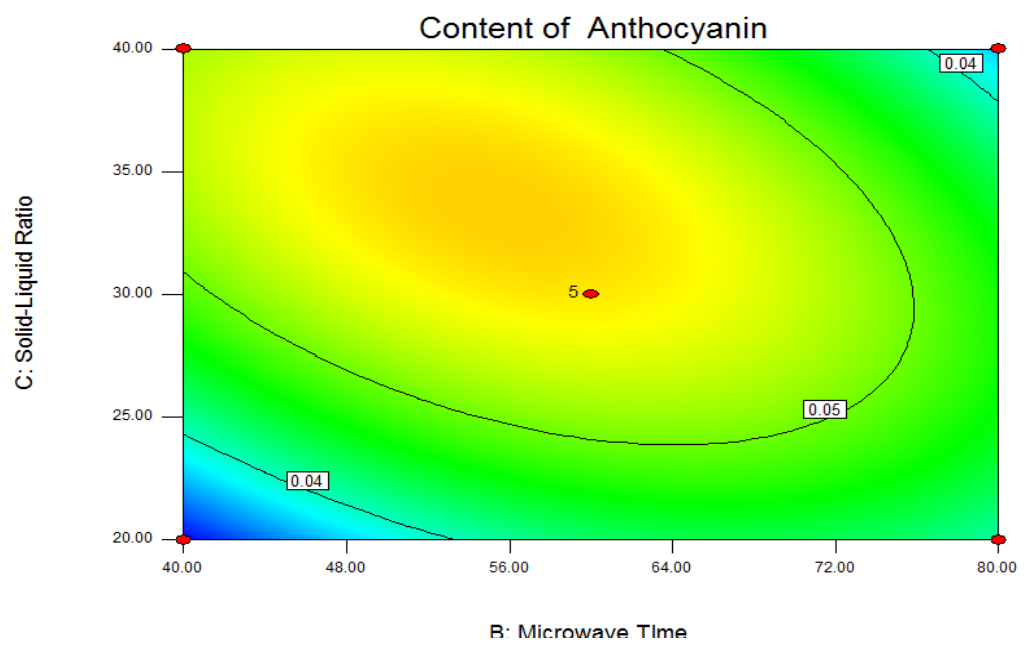

(b)

Fig. 5: 3D surface figure and contour map of the effect of microwave time and solvent-material ratio interaction

Table 3: Variance analysis of regression equation by RSM in the UAE of anthocyanins from red raspberry

\begin{tabular}{llllll}
\hline Treatments & Quadratic sum & Degree of freedom & M.S. & F-value & p-value \\
\hline Model & $1.133 \mathrm{E}-003$ & 9 & $1.259 \mathrm{E}-004$ & 5.40 & 0.0184 \\
$\mathrm{~A}-\mathrm{X}_{1}$ & $5.050 \mathrm{E}-005$ & 1 & $5.050 \mathrm{E}-005$ & 2.17 & 0.1844 \\
$\mathrm{~B}-\mathrm{X}_{2}$ & $8.611 \mathrm{E}-006$ & 1 & $8.611 \mathrm{E}-006$ & 0.37 & 0.8784 \\
$\mathrm{C}-\mathrm{X}_{3}$ & $1.549 \mathrm{E}-004$ & 1 & $1.549 \mathrm{E}-004$ & 6.65 & 0.5624 \\
$\mathrm{AB}-\mathrm{X}_{1} \mathrm{X}_{2}$ & $4.489 \mathrm{E}-005$ & 1 & $4.489 \mathrm{E}-005$ & 1.93 & 0.0366 \\
$\mathrm{AC}-\mathrm{X}_{1} \mathrm{X}_{3}$ & $1.482 \mathrm{E}-005$ & 1 & $1.482 \mathrm{E}-005$ & 0.64 & 0.2077 \\
$\mathrm{BC}-\mathrm{X}_{2} \mathrm{X}_{3}$ & $1.836 \mathrm{E}-004$ & 1 & $1.836 \mathrm{E}-004$ & 7.88 & 0.4513 \\
$\mathrm{~A}^{2}-\mathrm{X}_{1}{ }^{2}$ & $8.152 \mathrm{E}-005$ & 1 & $8.152 \mathrm{E}-005$ & 3.50 & 0.0263 \\
$\mathrm{~B}^{2}-\mathrm{X}_{2}{ }^{2}$ & $2.368 \mathrm{E}-004$ & 1 & $2.368 \mathrm{E}-004$ & 10.16 & 0.0153 \\
$\mathrm{C}^{2}-\mathrm{X}_{3}{ }^{2}$ & $2.918 \mathrm{E}-004$ & 1 & $2.918 \mathrm{E}-004$ & 12.52 & 0.0095 \\
Residual & $1.631 \mathrm{E}-004$ & 7 & $2.330 \mathrm{E}-005$ & & 0.21 \\
Lack of fit & $2.207 \mathrm{E}-005$ & 3 & $7.356 \mathrm{E}-006$ & & 0.8857 \\
Pure error & $1.410 \mathrm{E}-004$ & 4 & $3.526 \mathrm{E}-005$ & & \\
Cor total & $1.296 \mathrm{E}-003$ & 16 & & & \\
\hline
\end{tabular}

M.S.: Mean square

The best MAE value was obtained by the model with a microwave power of $519.79 \mathrm{~W}$, microwave time of 51.63 sand solvent-material ratio of $1: 34.99$. Under these optimal conditions, the anthocyanin content in the model reached $0.0575085 \mathrm{mg} / \mathrm{g}$. Through comprehensive consideration of various factors, the optimal extraction conditions were modified to a microwave power of $520 \mathrm{~W}$, microwave time of 52 sand solvent-material ratio of 1:35.

Optimization of UAE condition from red raspberry

by RSM: Using the response surface design software, 
the quadratic sum, degree of freedom, mean square, Fvalue, $\mathrm{p}$-value and regression equation analysis of variance were obtained for the UAE of anthocyanins from red raspberry (Table 3 ).

The regression equation is as follows (Eq. 7):

$$
\mathrm{R}_{2}=0.038-\left(1.812 \times 10^{-3}\right) \mathrm{X}_{4}-\left(6.362 \times 10^{-3}\right) \mathrm{X}_{5}+
$$
$\left(2.575 \times 10^{-3}\right) \mathrm{X}_{6}-\left(8.22 \times 10^{-3}\right) \mathrm{X}_{4} \mathrm{X}_{5}+\left(3.400 \times 10^{-3}\right)$ $\mathrm{X}_{4} \mathrm{X}_{6}-\left(4.200 \times 10^{-3}\right) \mathrm{X}_{5} \mathrm{X}_{6}-\left(2.988 \times 10^{-3}\right) \mathrm{X}_{4}^{2}-$ $\left(9.328 \times 10^{-3}\right) \mathrm{X}_{5}^{2}-\left(2.862 \times 10^{-3}\right) \mathrm{X}_{6}^{2}$

According to the data shown in Table 3, the ultrasound time, ultrasound temperature and solventmaterial ratio had a significant effect on the anthocyanin content in the red raspberry extracts. The model significance test $\mathrm{p}$-value was significant, while the lack of fit p-value was not significant, demonstrating that the model and the test fitted well and that the model better described the factors and the real relationship between the response values. The degree of influence of each variable on the experiment decreased in the following order: ultrasound temperature $\left(\mathrm{X}_{5}\right)>$ ultrasound time with ultrasound temperature $\left(\mathrm{X}_{4} \times \mathrm{X}_{5}\right)>$ ultrasound temperature with solvent-material ratio $\left(\mathrm{X}_{5} \times \mathrm{X}_{6}\right)>$ solvent-material ratio $\left(\mathrm{X}_{6}\right)>$ ultrasound time with solvent-material ratio $\left(\mathrm{X}_{4} \times \mathrm{X}_{6}\right)>$ ultrasound time $\left(\mathrm{X}_{4}\right)$. The ultrasound temperature had the largest effect on the UAE process among the variables, while ultrasound time had the weakest effect. The 3D surface figures and contour maps of each variable are shown in Fig. 6 to 8.

The best UAE value was obtained by the model with an ultrasound time of $14.16 \mathrm{~min}$, ultrasound temperature of $35.33^{\circ} \mathrm{C}$ and material-solvent ratio of $1: 38.94$. Under the optimum conditions, the anthocyanin content in the model reached 0.0402881 $\mathrm{mg} / \mathrm{g}$. Through comprehensive consideration of various factors, the optimal extraction conditions were modified to an ultrasound time of $14 \mathrm{~min}$, ultrasound temperature of $35^{\circ} \mathrm{C}$ and material-solvent ratio of 1:40.

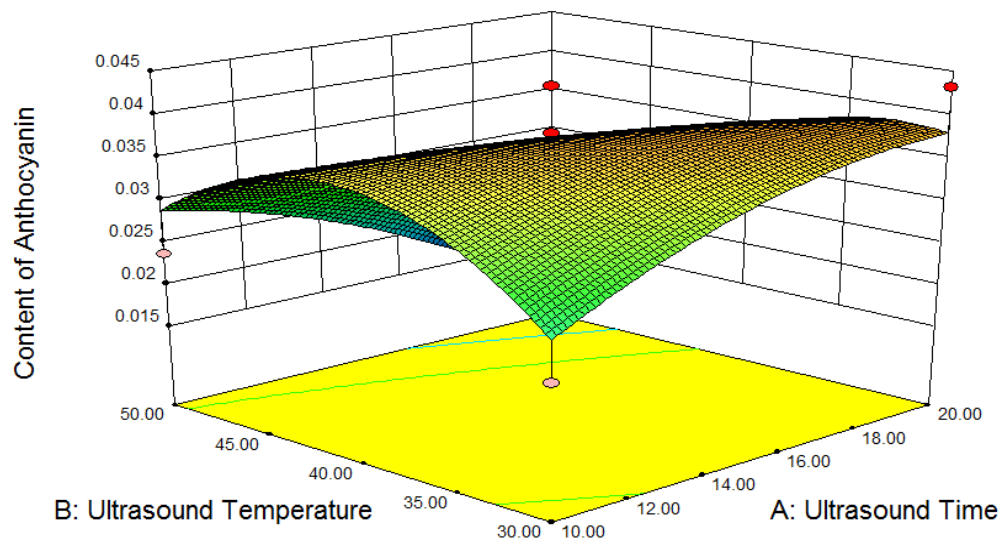

(a)

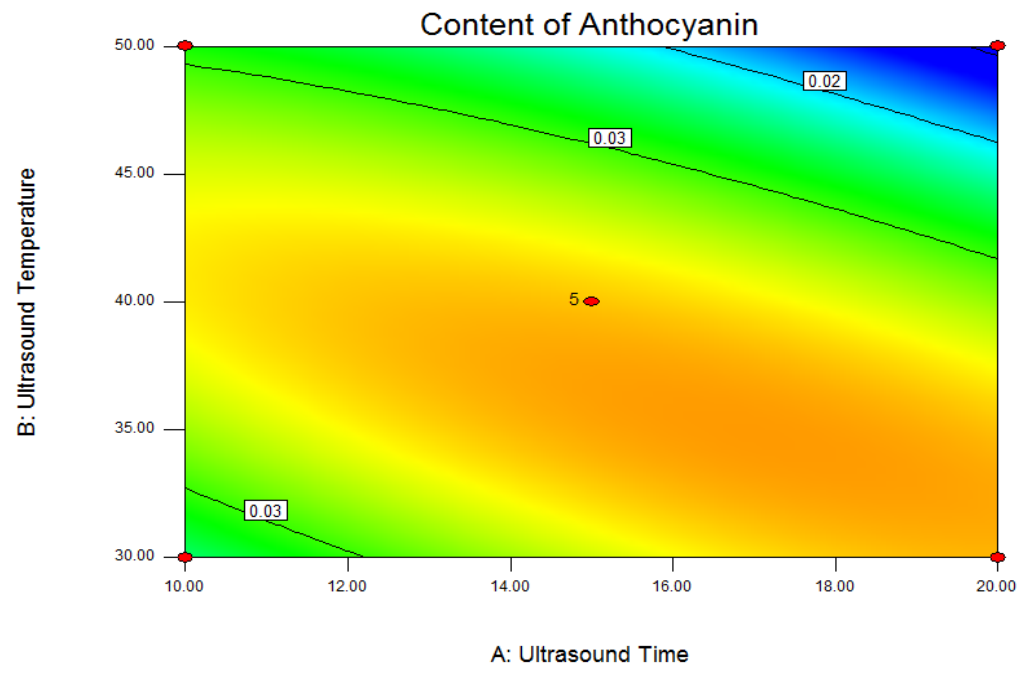

(b)

Fig. 6: 3D surface figure and contour map of the effect of ultrasound time and ultrasound temperature interaction 
Adv. J. Food Sci. Technol., 14(6): 166-180, 2018

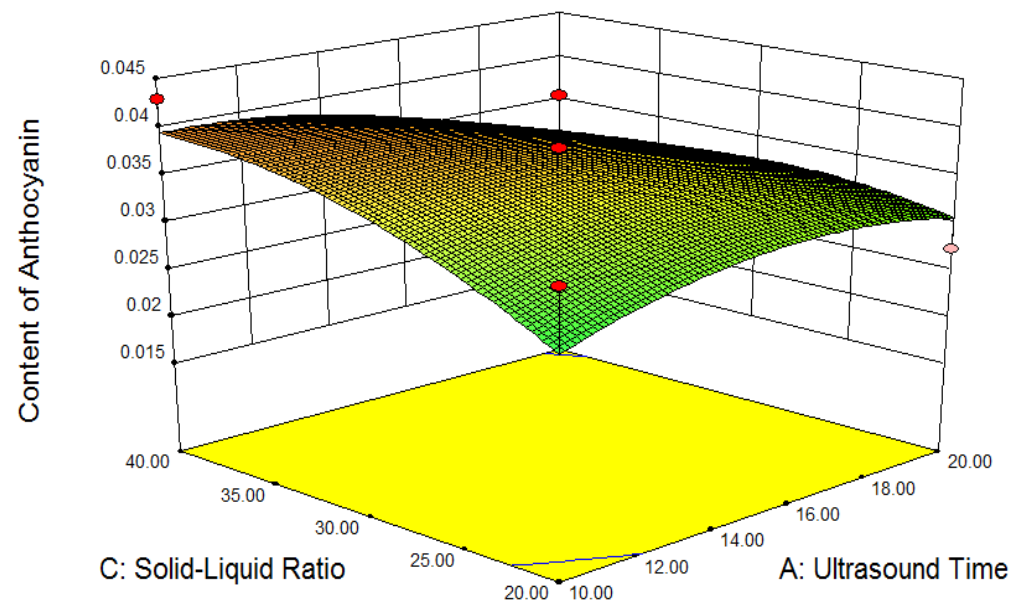

(a)

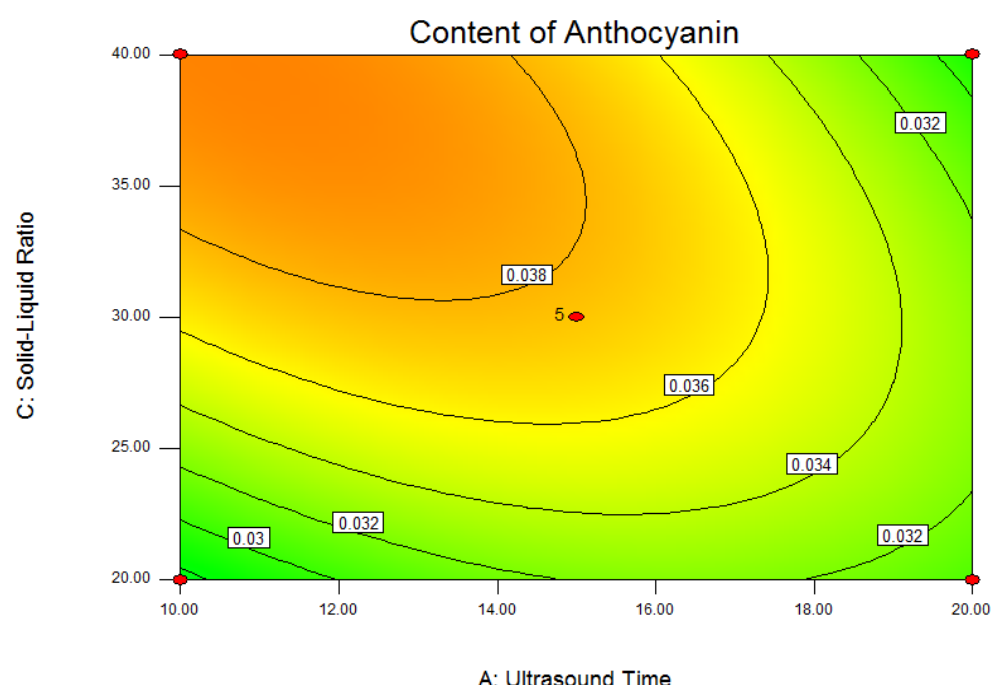

(b)

Fig. 7: 3D surface figure and contour map of the effect of ultrasound time and solvent-material ratio interaction

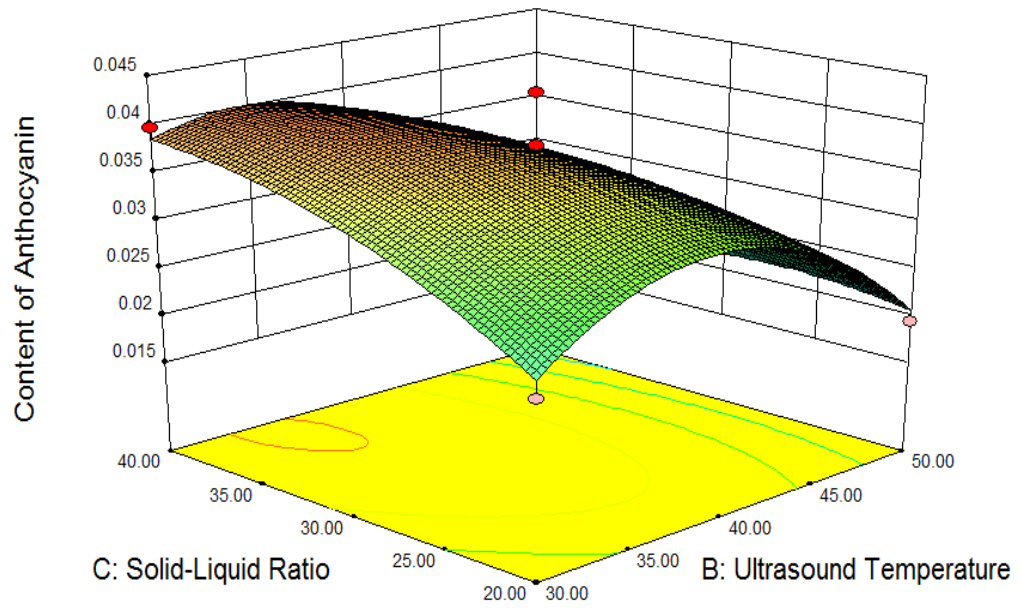

(a) 
Adv. J. Food Sci. Technol., 14(6): 166-180, 2018

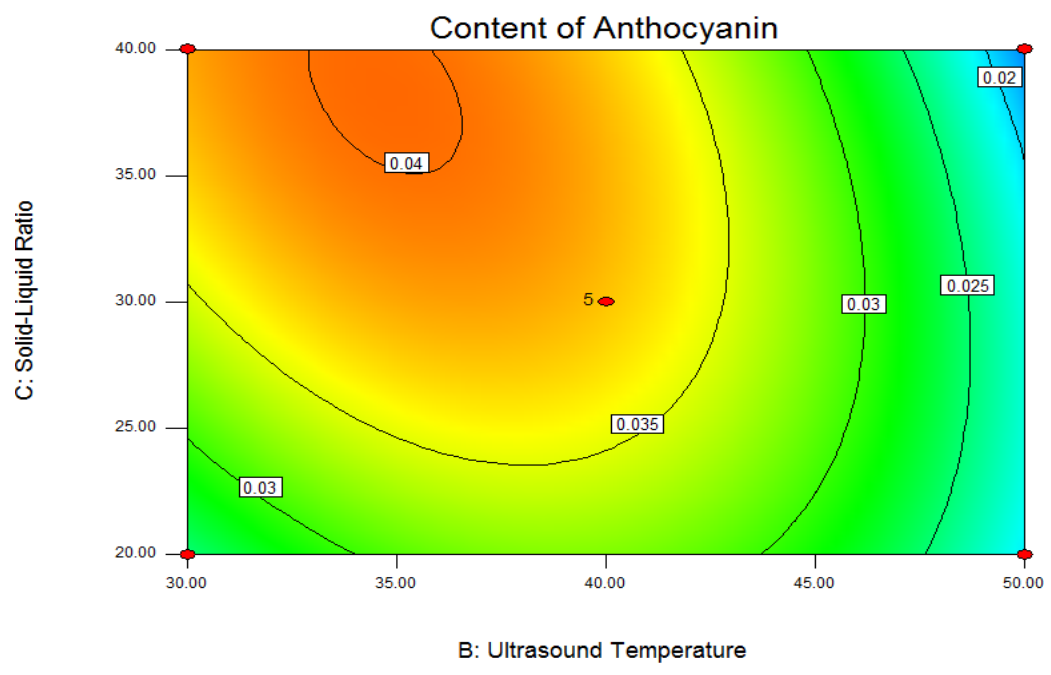

(b)

Fig. 8: 3D surface figure and contour map of the effect of ultrasound temperature and solvent-material ratio interaction

Experiment verification: The optimized extraction values obtained in sections 3.3 .1 and 3.3.2, were subjected to a verification test and compared with the predicted value. For the MAE of red raspberry anthocyanins, the predicted anthocyanin content was $0.0575085 \mathrm{mg} / \mathrm{g}$, while the final anthocyanin content obtained from triplicate experiments was $0.0598 \mathrm{mg} / \mathrm{g}$. For the UAE, the predicted anthocyanin content from red raspberry was $0.0402881 \mathrm{mg} / \mathrm{g}$, while the actual value was $0.0412 \mathrm{mg} / \mathrm{g}$. Therefore, the anthocyanin contents obtained by MAE were nearly 1.5 times higher than those obtained by UAE.

Antioxidant activity from red raspberry anthocyanin extract: Figure 9 shows the logarithmic relationship between the samples concentration and free radical clearance. Analysis of the fitting results shown in Table 4 indicated that the DPPH scavenging activities were equal at the same concentrations, with the scavenging capacities of the MAE and UAE red raspberry anthocyanins extracts were about 2.8 and 1.5fold that of the Vc control. These results indicated that the raspberry anthocyanins had a strong reducing ability and a strong scavenging effect toward DPPH free radicals. However, anthocyanins obtained by MAE had a better scavenging ability than those obtained by UAE.

The hydroxyl radical scavenging activities of each sample are shown in Fig. 10. The test results were nonlinear. The fitting results in Table 4 show that, in the same hydroxyl free radical scavenging reaction system, the red raspberry anthocyanin scavenging $\mathrm{AE}$ value was 0.366 for MAE and 0.237 for UAE, while the control Vc, had an AE value of 0.078. The hydroxyl free radical scavenging capacity of raspberry anthocyanins obtained by MAE and UAE were about 4.69 and 3-fold that of the Vc control. Therefore, the anthocyanins played an important role in scavenging hydroxyl free radicals and the scavenging ability of raspberry anthocyanins obtained by MAE was much better than that obtained by UAE.

The trend line for each sample in ABTS free radical clearing is shown in Fig. 11 and the fitting results are shown in Table 4. In the same ABTS scavenging reaction system, MAE and UAE raspberry anthocyanins had AE values of 0.248 and 0.195 , while the control Vc had an AE value of 0.192. Red raspberry anthocyanins obtained by MAE and UAE had ABTS free radical scavenging capacities about 1.2-fold and the same as that of $\mathrm{Vc}$, respectively. Anthocyanins extracted from red raspberry clearly showed ABTS scavenging activity, which was stronger when obtained by MAE compared with that obtained by UAE.

The half-scavenging concentrations (EC50) of the anthocyanin extracts were obtained for DPPH, hydroxyl and ABTS radicals in three in-vitro antioxidant experiments and the free radical scavenging activity (AE) was calculated. The free radical scavenging activities of agents extracted by MAE were: 0.0156 $\mathrm{mg} / \mathrm{mL}$ for DPPH, $0.366 \mathrm{mg} / \mathrm{mL}$ for hydroxyl and $0.248 \mathrm{mg} / \mathrm{mL}$ for ABTS radicals, respectively. These results were $2.78,4.69$ and 1.29 times those of $\mathrm{Vc}$ control, respectively. The free radical scavenging ability of anthocyanins obtained by UAE were 0.0087 $\mathrm{mg} / \mathrm{mL}$ for DPPH, $0.237 \mathrm{mg} / \mathrm{mL}$ for hydroxyl and $0.195 \mathrm{mg} / \mathrm{mL}$ for ABTS, respectively. These were 1.5 times, 3 times and the same as, the results obtained using the Vc control, respectively. Therefore, red raspberry anthocyanin extract showed an antioxidant effect, with a stronger free radical scavenging ability obtained by MAE than by UAE. Red raspberry anthocyanin extracts scavenged hydroxyl free radicals better than ABTS and DPPH radicals. 
Adv. J. Food Sci. Technol., 14(6): 166-180, 2018
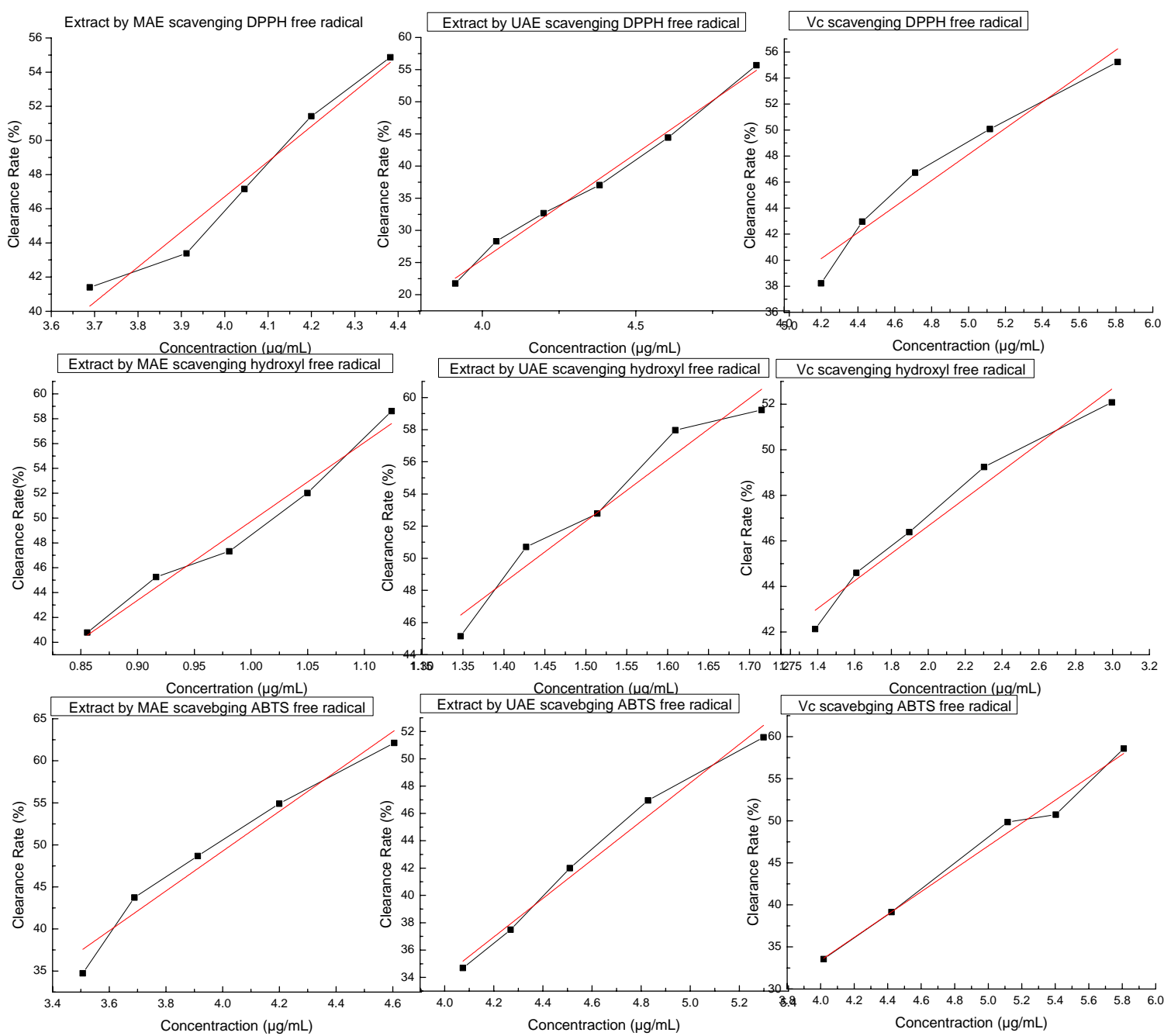

Fig. 9 to 11: Effect of different samples on DPPH, hydroxyl, and ABTS free radical scavenging

Table 4: Fitting results of different samples in different scavenging experiments

\begin{tabular}{|c|c|c|c|c|}
\hline Treatments & Samples & Fitting equation and correlation coefficient & $\mathrm{E}_{\mathrm{C} 50}$ & $\mathrm{AE}$ \\
\hline \multirow[t]{3}{*}{$\begin{array}{l}\text { DPPH free radical } \\
\text { scavenging }\end{array}$} & Extract by MAE & $\begin{array}{l}Y=20.60 \mathrm{LnX}-35.68 \\
\mathrm{R}^{2}=0.9552\end{array}$ & 64.06 & $1.56 \times 10^{-2}$ \\
\hline & Extract by UAE & $\begin{array}{l}\mathrm{Y}=32.99 \mathrm{LnX}-106.41 \\
\mathrm{R}^{2}=0.99084\end{array}$ & & \\
\hline & $\mathrm{Vc}$ & $\begin{array}{l}Y=10.02 \operatorname{LnX}-1.98 \\
R^{2}=0.93878\end{array}$ & $\begin{array}{l}114.95 \\
178.88\end{array}$ & $\begin{array}{l}8.7 \times 10^{-3} \\
5.6 \times 10^{-3}\end{array}$ \\
\hline \multirow[t]{6}{*}{$\begin{array}{l}\text { Hydroxyl free radical } \\
\text { scavenging }\end{array}$} & Extract by MAE & $\begin{array}{l}\mathrm{Y}=63.53 \mathrm{LnX}-13.80 \\
\mathrm{R}^{2}=0.97161\end{array}$ & 2.73 & 0.366 \\
\hline & Extract by UAE & $\begin{array}{l}\mathrm{Y}=38.22 \mathrm{LnX}-5.02 \\
\mathrm{R}^{2}=0.92878\end{array}$ & 4.22 & 0.237 \\
\hline & $\mathrm{Vc}$ & $\begin{array}{l}\mathrm{Y}=6.03 \mathrm{LnX}+34.59 \\
\mathrm{R}^{2}=0.96035\end{array}$ & 12.86 & 0.078 \\
\hline & Extract by MAE & $\begin{array}{l}Y=14.10 \mathrm{LnX}-22.27 \\
\mathrm{R}^{2}=0.97934\end{array}$ & 5.13 & 0.248 \\
\hline & Extract by UAE & $\begin{array}{l}\mathrm{Y}=32.99 \mathrm{LnX}-106.41 \\
\mathrm{R}^{2}=0.99084\end{array}$ & 4.03 & 0.195 \\
\hline & $\mathrm{Vc}$ & $\begin{array}{l}\mathrm{Y}=10.02 \mathrm{LnX}-1.98 \\
\mathrm{R}^{2}=0.93878\end{array}$ & 5.22 & 0.192 \\
\hline
\end{tabular}

\section{CONCLUSION}

MAE and UAE methods each have unique advantages. For example, MAE is a low-temperature, energy-saving, nonpolluting method with a low extraction time that can also obtain the maximum degree of anthocyanin purity through protection. Meanwhile, UAE can reduce the extraction time and 
has a protective effect on active components that are heat sensitive and easily hydrolyzed or oxidized. However, experimental results showed that MAE was better than UAE.

Optimum conditions for MAE were a microwave power of $520 \mathrm{~W}$, microwave time of $52 \mathrm{sec}$ and material-solvent ratio of 1:35. The predicted anthocyanin content was $0.0575 \mathrm{mg} / \mathrm{g}$, while the actual content was 0.0598 . For UAE, the optimum conditions were an ultrasound time of $14 \mathrm{~min}$, ultrasound temperature of $35^{\circ} \mathrm{C}$, the material-solvent ratio of 1:40. Using this method, the predicted anthocyanin content was $0.0402 \mathrm{mg} / \mathrm{g}$, while the actual content was 0.0412 $\mathrm{mg} / \mathrm{g}$.

Sun et al. (2007) have previously used the MAE method to optimize the process parameters of materialsolvent ratio, microwave time and microwave power to obtain a final anthocyanin content of $43.4202 \mathrm{mg} / 100 \mathrm{~g}$. Wan et al. (2016) have previously used the UAE method to optimize the process parameters of materialultrasonic power, internal time, extraction time and temperature to obtain a final anthocyanin content of $0.163 \mathrm{mg} / \mathrm{g}$. Teng et al. (2013) have previously used the MAE method to optimize the process and tested different solvent, final anthocyanin content of 17.93 $\mathrm{mg} / 100 \mathrm{~g}$. In that trial, the researchers used an optimization process consistent with that reported herein, which shows that chosen parameters optimized have received universal recognition. However, the final results obtained were not the same, perhaps because different raspberry cultivars were chosen and the tests were performed in different seasons, meaning that the process was similar, but with subtle differences.

Chen et al. (2007) have previously used UAE to determine the anthocyanin content of fresh fruit as 34.5 $\mathrm{mg} / 100 \mathrm{~g}$ and the material-solvent ratio, extraction time and ultrasound power were optimized. Teng et al. (2014) also studied the factors of ethanol concentration, ultrasound time and extraction temperature in a UAE method. The total anthocyanin content total (15.23 cyanidin-3-glucoside equivalent/g $\mathrm{mg}$ ) had been obtained experimentally previously. The results were different from those reported herein, which might be due to the differences, such as in the optimization conditions and parameters, or the effect of different storage periods or sample handling procedures (Withy et al., 1993). Using response surface design software, a series of linear regression equations and $\mathrm{P}$-values were obtained. According to these data and actual values, both models were well suited and reached a significant level. In the final result, the anthocyanin content from MAE was three times that obtained by UAE. Finally, MAE was selected for further study. Not only is the extraction rate of MAE higher than that of UAE, but MAE also requires less time and resources.

Previous research into methods for extracting red raspberry anthocyanins focused on single methods. In contrast, we have studied two extraction methods and compared their intrinsic differences for the rapid extraction of anthocyanins, which lays the foundations for industrial production.

Through in-vitro antioxidant experiments of red raspberry anthocyanin extracts, we discovered that, compared with the $\mathrm{Vc}$ control, red raspberry anthocyanin extract had significant free radical scavenging activity. Antioxidant activity experiments showed that the red raspberry anthocyanin extracts had strong antioxidant activities against DPPH, hydroxyl and ABTS free radicals in scavenging assays, with the activities becoming stronger with increasing anthocyanin concentration. Through analysis of the experimental data, the scavenging ability of red raspberry anthocyanin extracts for different radicals increased in the order hydroxyl $>$ ABTS $>$ DPPH. Furthermore, the antioxidant capacities of the extract from MAE were higher than for those obtained by UAE.

Aguirre et al. (2010) found that no relationship existed between the ABTS clearance rate and total polyphenol and anthocyanins contents of the raspberry extract, but that the contents of free anthocyanins and oligomers of anthocyanins showed good correlation. Pantelidis et al. (2007) found that the total reduction abilities of different varieties of berries and the anthocyanin contents were smaller than those of other fruits. Furthermore, many researchers have also reported that there is close relationship between the intrinsic antioxidant activity of raspberry among seasons and different raspberry varieties (Dobson et al., 2012; Chen et al., 2013).

There have been few studies on raspberry antioxidants and little is known about raspberry active components and their effect on structure re-oxidation. Therefore, each component of red raspberry requires further study to clearly determine the composition and structure of the active ingredients, antioxidant mechanism, antioxidant activity and their correlation.

Conflict of interest: We declare that none of the work contained in this manuscript is published in any language or currently under consideration at any other journal and there are no conflicts of interest to declare. All authors have contributed to, read and approved this submitted manuscript in its current form.

\section{ACKNOWLEDGMENT}

This study was financially supported by The National Key Research and Development Program of China (2016YFF0202300) and Science and Technology Planning Project of Hebei Province (16226806D-1).

We thank Simon Partridge, PhD, from Liwen Bianji, Edanz Editing China (www.liwenbianji.cn/ac), for editing the English text of a draft of this manuscript. 
Adv. J. Food Sci. Technol., 14(6): 166-180, 2018

\section{REFERENCES}

Aguirre, M.J., Y.Y. Chen, M. Isaacs, B. Matsuhiro, L. Mendoza and S. Torres, 2010. Electrochemical behaviour and antioxidant capacity of anthocyanins from chilean red wine, grape and raspberry. Food Chem., 121(1): 44-48.

Chen, F., Y. Sun, G. Zhao, X. Liao, X. Hu, J. Wu et al., 2007. Optimization of ultrasound-assisted extraction of anthocyanins in red raspberries and identification of anthocyanins in extract using high-performance liquid chromatography-mass spectrometry. Ultrason. Sonochem., 14(6): 767-778.

Chen, L., X. Xin, Y. Wang and Q. Yuan, 2011. Analysis of content and compositions of anthocyanins in red raspberry. Food Fermentation Ind., 99(Suppl 3): A231-A231.

Chen, L., X. Xin, H. Zhang and Q. Yuan, 2013. Phytochemical properties and antioxidant capacities of commercial raspberry varieties. J. Funct. Foods, 5(1): 508-515.

Chen, Q., A. Shen and G. Chen, 2014. Optimization of anthocyanins extraction from red raspberry by response surface methodology. China Brewing, 33(12): 76-79.

De Souza, V.R., P.A. Pereira, A.C. Pinheiro, C.A. Nunes, R. Pio and F. Queiroz, 2014a. Evaluation of the jelly processing potential of raspberries adapted in Brazil. J. Food Sci., 79(3): S407-S412.

De Souza, V.R., P.A. Pereira, T.L. de Silva, L.C. de Oliveira Lima, R. Pio and F. Queiroz, 2014b. Determination of the bioactive compounds, antioxidant activity and chemical composition of Brazilian blackberry, red raspberry, strawberry, blueberry and sweet cherry fruits. Food Chem., 156(3): 362-368.

Dobson, P., J. Graham, D. Stewart, R. Brennan, C.A. Hackett et al., 2012. Over-seasons analysis of quantitative trait loci affecting phenolic content and antioxidant capacity in raspberry. J. Agr. Food Chem., 60(21): 5360-5366.

Dong, C.J., L.I. Feng and Y.J. Shao, 2014. Comparison of extraction methods and color stability study on pigment of red raspberry. Food Res. Develop., 4: 69-71.

Figueira, M.E., M.B. Câmara, R. Direito, J. Rocha, A.T. Serra et al., 2014. Chemical characterization of a red raspberry fruit extract and evaluation of its pharmacological effects in experimental models of acute inflammation and collagen-induced arthritis. Food Funct., 5(12): 3241-3251.

Hernández-Herrero, J.A. and M.J. Frutos, 2011. Degradation kinetics of pigment, colour and stability of the antioxidant capacity in juice model systems from six anthocyanin sources. Int. J. Food Sci. Tech., 46(12): 2550-2557.
Jakobek, L. and M. Seruga, 2012. Influence of anthocyanins, flavonols and phenolic acids on the antiradical activity of berries and small fruits. Int. J. Food Prop., 15(1): 122-133.

Jean-Gilles, D., L. Li, H. Ma, T. Yuan, C.O. 3rd Chichester and N.P. Seeram, 2012. Antiinflammatory effects of polyphenolic-enriched red raspberry extract in an antigen-induced arthritis rat model. J. Agr. Food Chem., 60(23): 5755-5762.

Mazur, S.P., A. Nes, A.B. Wold, S.F. Remberg and K. Aaby, 2014. Quality and chemical composition of ten red raspberry (Rubus idaeus L.) genotypes during three harvest seasons. Food Chem., 160(10): 233-240.

Ozarda, O., A. Barla Demirkoz and M. Özdemir, 2015. Sensory characteristics and antioxidant capacity of red raspberry extract as a preservative in fruity flavoured beverages. J. Food Sci. Technol., 52(10): 6687-6694.

Pantelidis, G.E., M. Vasilakakis, G.A. Manganaris and G. Diamantidis, 2007. Antioxidant capacity, phenol, anthocyanin and ascorbic acid contents in raspberries, blackberries, red currants, gooseberries and cornelian cherries. Food Chem., 102(3): 777783.

Seeram, N.P., L.S. Adams, Y. Zhang, R. Lee, D. Sand et al., 2006. Blackberry, black raspberry, blueberry, cranberry, red raspberry, and strawberry extracts inhibit growth and stimulate apoptosis of human cancer cells in vitro. J. Agr. Food Chem., 54(25): 9329-9339.

Shi, Y., L.I. Yadong, X. Xin and L.I. Xiaoyan, 2009. Study on clarification of fermented red raspberry wine. China Brewing, 28(1): 122-124.

Sun, Y., 2006. Study on the processing of the extraction of anthocyanins from red raspberry (Rubus corchorifolius L.). Food Fermentation Ind., 32(1): 129-133.

Sun, Y., X. Liao, Z. Wang, X. Hu and F. Chen, 2007. Optimization of microwave-assisted extraction of anthocyanins in red raspberries and identification of anthocyanin of extracts using high-performance liquid chromatography-mass spectrometry. Eur. Food Res. Technol., 225(3-4): 511-523.

Teng, H., W.Y. Lee and Y.H. Choi, 2013. Optimization of microwave-assisted extraction for anthocyanins, polyphenols, and antioxidants from raspberry (Rubus Coreanus Miq.) using response surface methodology. J. Sep. Sci., 36(18): 3107-3114.

Teng, H., W.Y. Lee and Y.H. Choi, 2014. Optimization of ultrasonic-assisted extraction of polyphenols, anthocyanins, and antioxidants from raspberry (Rubus coreanus Miq.) using response surface methodology. Food Anal. Method., 7(7): 15361545.

Tosun, M., S. Ercisli, H. Karlidag and M. Sengul, 2009. Characterization of red raspberry (Rubus idaeus L.) genotypes for their physicochemical properties. J. Food Sci., 74(7): C575-C579. 
Wan, S., Z. Yang, B.Q. Zhu and J. Ouyang, 2016. Parameters optimization of ultrasound- assisted extraction of anthocyanins from red raspberry by response surface methodology. Sci. Technol. Food Ind., 37(3): 220-224.

Wang, J., L.I. Liangliang, L. Changshan, S.O. Forestry and N.F. University, 2015. Determination of ellagic acid from six red raspberry cultivars grown in northeast china using rp-hplc. Food Sci., 36(12): 93-96.

Withy, L.M., T.T. Nguyen, R.E. Wrolstad and D.A. Heatherbell, 1993. Storage changes in anthocyanin content of red raspberry juice concentrate. J. Food Sci., 58(1): 190-192.
Xiao, J.X., G.Q. Huang, H.W. Qiu and C.R. Wang, 2011. Extraction and antioxidant activity of anthocyanins from red raspberry. Food Sci., 32(8): 15-18.

Xiao-Ping, L.I., L. Qi, X.L. Xin and Y.H. Wang, 2010. Study on the antioxidation activity of extraction of ellagic acid from red raspberry. Food Sci. Technol., 5: $182-185$.

Yuan, X.H., L. Zhang and Y.Q. Xu, 2011. Study on microwave-assisted extraction of pigment from red raspberry fruits optimized by response surface analysis. Food Ind., 7: 7-9. 